\section{Density of liquid gold measured by a non-contact technique}

\author{
PF Paradis ${ }^{a}$, T Ishikawa ${ }^{a}, N^{\prime}$ Koike $^{b}$
}

Japan Aerospace Exploration Agency, Institute of Space and Astronautical Science, ISS Science Project Office, 2-1-1 Sengen, Tsukuba, Ibaraki, 305-8505, Japan. Email: paradis.paulfrancois@jaxa.jp. bChiba Institute of Technology, Tsudanuma, Narashino, Chiba, 275-0016, Japan

\begin{abstract}
Electrostatic levitation together with multi-beam laser heating and ultraviolet imaging made possible to handle a sample of liquid gold, without any contamination, and to determine its density over a large temperature range. Over the 1337-1800 K interval, the density of Au was measured as $\rho(T)=1.74 \times 10^{4}-1.44\left(T-T_{m}\right) k g \cdot m^{-3}$, where $T_{m}$, the melting temperature, was $1337 \mathrm{~K}$. These data yield a calculated volume expansion coefficient of $8.3 \times 10^{-5} \mathrm{~K}^{-1}$. The values agree well with the literature values.
\end{abstract}

\section{Keywords}

density, liquid, gold, levitation

\section{Introduction}

Gold is believed to be synthesized by a rapid neutron-capture reaction during supernova explosions [1]. Some of the remnant gold of these stellar events is nowadays isotropically distributed in the Earth's crust at the background level of $3 \mathrm{x}$ $10^{-3} \mathrm{ppm}[2]$. Due to its soft, shiny (reflects infrared radiation), yellow, malleability, ductility, and alloyable characteristics, it has been utilized widely in monetary standards, jewelry, spacecraft shieldings, and dentistry to name but a few [3]. Recent applications include the ubiquitous use of gold layers for contacts in micro-electronics and nanoparticles in medical and biological fields.

To better understand the metallurgical processes (refining, slag/metal kinetics, solidification, etc.) needed in alloy design [4], and to help describe the radial distribution function, density measurements of liquid gold have been undertaken for a long time. Although a noble metal, its ability to form many compounds [3] becomes a drawback when measuring the physical properties (e.g., surface tension, viscosity, density) of its liquid phase because of possible contamination. This is especially true when pulse heating, buoyancy, drop, or dilatometry techniques are used.

Originally developed by space agencies to counter residual accelerations acting on a sample during materials processing in space [5-7], electrostatic levitators and the associated noncontact diagnostic techniques have found several spin-offs on the ground, in particular for physical property measurements and solidification studies. Besides the advantage of removing any physical contact between a sample and a support, they offer the combined attributes of processing millimeter-size objects, handling virtually convection-free molten materials for hours, in addition to excellent temperature homogeneity and wide view around the samples for diagnostics.

In this work, electrostatic levitation and laser heating circumvented the risk of sample contamination, allowing processing a gold sample under high vacuum, melting it, and measuring its density over a wide temperature range.

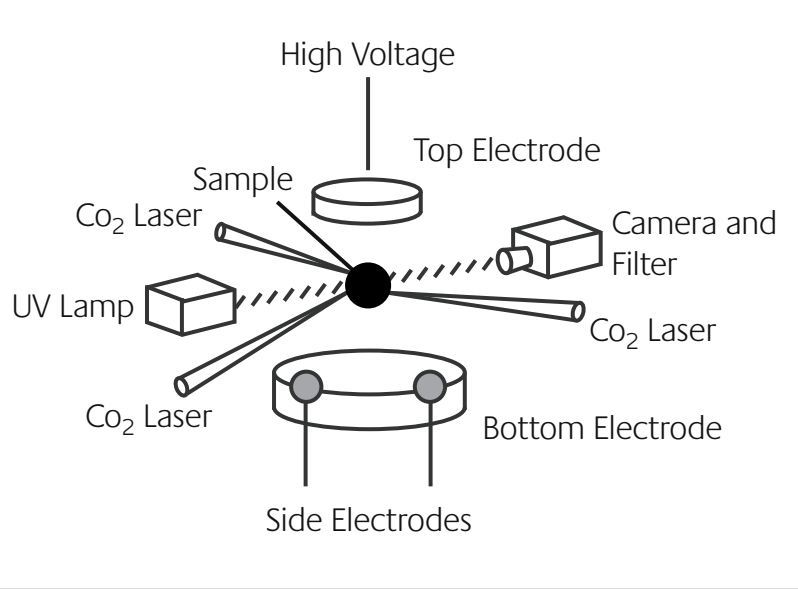

Figure 1 Experimental set-up 
Table1

Comparison with Literature Values of the Density of Cold

\begin{tabular}{|c|c|c|c|c|}
\hline $\begin{array}{c}\text { Density @ } T_{m} \\
\quad\left(\mathrm{~kg} \cdot \mathrm{m}^{-3}\right)\end{array}$ & $\begin{array}{c}\text { Temperature Coeff. } \\
\left(\mathrm{kg} \cdot \mathrm{m}^{-3} \mathrm{~K}^{-1}\right)\end{array}$ & $\begin{array}{l}\text { Temperature } \\
\text { (K) }\end{array}$ & Reference & Technique \\
\hline 17400 & -1.44 & $1337-1800$ & This work & Electrostatic levitation \\
\hline 17200 & -1.44 & $1337-3820$ & Kaschnitz et al. [9] & Pulse heating \\
\hline 17310.5 & -1.343 & $1337-1573$ & Gomez et al. [10] & Direct Buoyancy \\
\hline 17361 & -1.612 & $1337-1573$ & Gebhardt et al.[11] & Indirect Buoyancy \\
\hline 17360 & - & 1337 & Vinet [12] & Pendant drop \\
\hline 17400 & - & 1337 & Lucas [13] & Direct Buoyancy \\
\hline 17400 & - & 1337 & McGonigal [14] & Dilatometry \\
\hline 17200 & -1.27 & $1337-1500$ & Khilya et al. [15] & Sessile drop \\
\hline 17280 & -1.226 & $1337-1573$ & Gebhardt et al. [17] & Indirect Buoyancy \\
\hline 17400 & -1.10 & $1358-1779$ & Brillo et al. [18] & $\begin{array}{l}\text { Electromagnetic } \\
\text { levitation }\end{array}$ \\
\hline- & -1.2 & - & Steinberg [19] & Calculation \\
\hline- & -1.7 & - & Steinberg [19] & Calculation \\
\hline
\end{tabular}

\section{Experimental}

\section{Levitation furnace}

For these experiments, specimens were prepared by arc melting Au wire (99.95\% purity, Nilaco Corp., Japan) into spheroids with diameters of less than $2 \mathrm{~mm}$. For processing, a sample was charged by thermionic emission and was levitated in a high vacuum environment $\left(\sim 10^{-5} \mathrm{~Pa}\right)$ using electrostatic forces between electrodes $[5,6]$ via a feedback loop (Fig. 1)[7]. The sample was heated and melted using the focused radiation $(10.6 \mu \mathrm{m})$ coming from three $\mathrm{CO}_{2}$ laser beams (200 W). This configuration offered sample position stability and enhanced temperature homogeneity. The radiance temperature of the sample was measured using two automatic pyrometers (Chino Corp, Model IR-CS, operating at $0.90 \mu \mathrm{m}$ and Model IR-AP, operating at 0.96 $\mu \mathrm{m})$ with respective acquisition rates of 10 and $120 \mathrm{~Hz}$. Calibration to the true temperature was performed with Planck's law using the known melting temperature of Au (1337.33 K)[8].

\section{Density measurements}

The density of Au was determined by imaging an ultraviolet backlit sample with a high-resolution charged coupled device camera equipped with a high-pass filter (380 nm)[6]. Once melted, the sample took a spherical shape due to surface tension and its images and temperature were simultaneously recorded. The shutters of all lasers were then closed allowing radiative cooling of the sample. After the experiment, the sample area was extracted from each digitized video images and matched to a temperature profile. These images were calibrated by levitating a sphere of precisely known diameter under identical conditions. Since the sample was axi-symmetric and because its mass

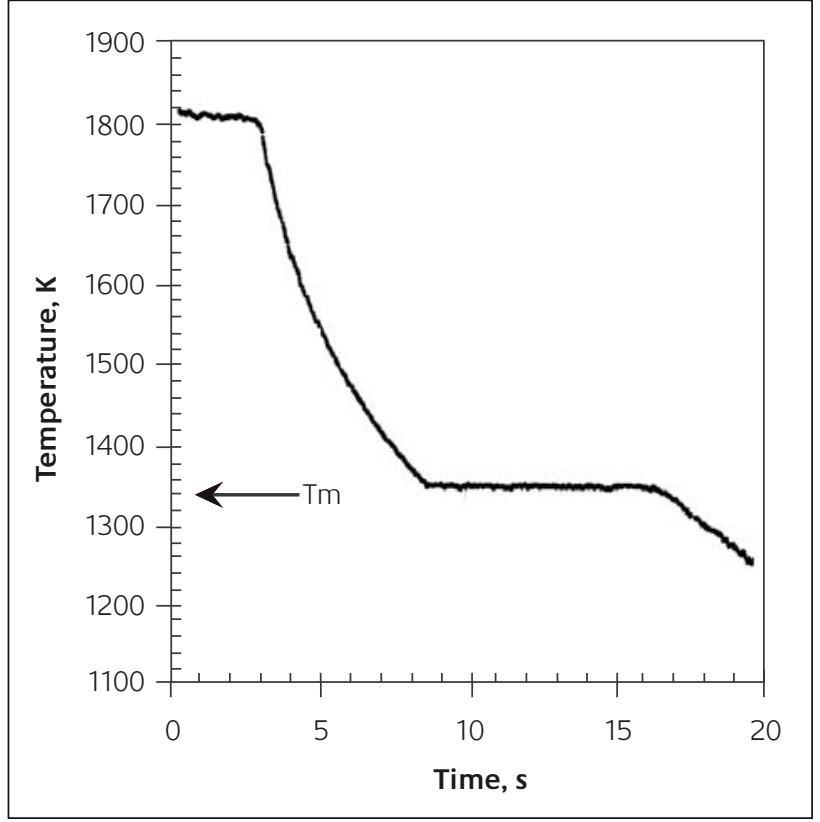

Figure 2 Typical temperature profile for a gold sample (dia.:ca. 1.35 mm; mass: $21.12 \mathrm{mg}$ )

was known, the density could be found for each temperature.

\section{Results and discussion}

Figure 2 shows a thermal profile for a Au sample exhibiting an average radiative cooling rate of nearly $90 \mathrm{~K} / \mathrm{s}$ and the solidification plateau. The density measurements, taken over the 1337 to $1800 \mathrm{~K}$ temperature range, are shown in Figure 3. The density of Au, like that of other pure metals, exhibited a linear behavior as a function of temperature and can be fitted as: 


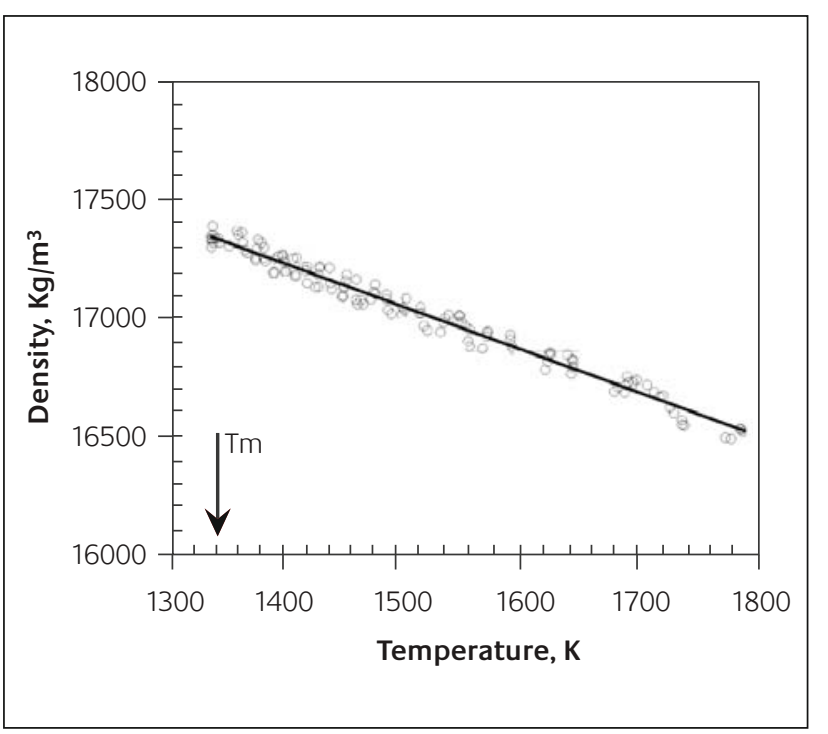

Figure 3 Density of liquid gold as a function of temperature

$$
\rho(T)=1.74 \times 10^{4}-1.44\left(T-T_{m}\right)\left(\mathrm{kg} \cdot \mathrm{m}^{-3}\right)
$$

where $T_{m}$ is the melting temperature (1337 K). In these experiments, the uncertainty was estimated to be less than 2 $\%$ from the resolution of the video grabbing capability ( $640 \mathrm{X}$ 480 pixels) and from the uncertainty in mass measurement $( \pm 0.0001 \mathrm{~g})$. From these data, the volume expansion coefficient was calculated as $8.3 \times 10^{-5} \mathrm{~K}^{-1}$. The values that appeared in the literature were listed in Table 1 for comparison. At the melting temperature, our density datum was, within respective experimental uncertainties, identical to all those reported in the literature [9-18]. Our temperature coefficient was also identical to that measured by Kaschnitz et al. using a pulsed heating technique [9]. It is however, $7.2 \%$ higher than that reported by Gomez et al. [10] and $10.7 \%$ smaller than that of Gebhardt et al. [11]. It is also higher than $13.4 \%$ compared to the value of Khilya et al. [15,16], $17.1 \%$ with that of Gebhardt et al. [17], and $30.1 \%$ with that of Brillo et al. [18], Compared to the calculations obtained by Steinberg [19] using the data of both references [13] and [14], our coefficient is either $20 \%$ higher or $15.3 \%$ lower.

The discrepancies between our temperature coefficient and those reported elsewhere could be attributed to the difference in processing techniques. In this work, the samples were isolated from container walls and gases using a levitation method and radiative heating in high vacuum, and an imaging technique allowed density measurements over a large temperature interval. Therefore, possible sources of error could arise from the focusing of the sample, the digitization of the image, and the measurements of sample mass. Other authors [9,11,15-17] employed techniques (e.g., pendant drop, sessile drop, pulse heating) for which possible chemical reactions between the highly reactive molten metal and a support could have occurred. Material purity, gas solubility in the samples, and the level of vacuum could also explain the discrepancies [18]. In fact, surface contamination would certainly change the emissivity and the intrinsic emissivity variation with temperature of the liquid phase itself [20]

would lead to different temperature coefficients.

In conclusions, the density of liquid Au was accurately measured with a high vacuum electrostatic levitation furnace over a large temperature range without any risk of contamination. The data show good agreement with the literature values [16] and therefore confirm the validity of the techniques used. Contrary to the other techniques used so far to study gold, electrostatic levitation has the capability to maintain a sample without any physical contact with container walls and without severe convection for long duration (> 1 hour). More importantly, properties such as surface tension and viscosity, which are very sensitive to either contamination or convection, could be measured over wide temperature ranges. Improvement of the vacuum level would also allow the measurements in supercooled states. Such investigations have been initiated and the results will be reported later.

\section{Acknowledgements}

We would like to express our gratitude to Mr. Y. Watanabe (Advanced Engineering Services) for his technical help in some of the experiments.

\section{About the authors}

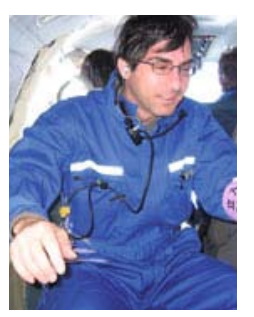

PF Paradis

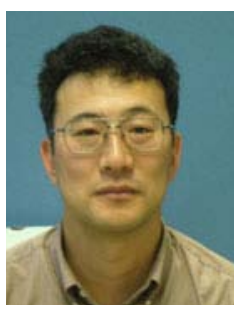

T Ishikawa

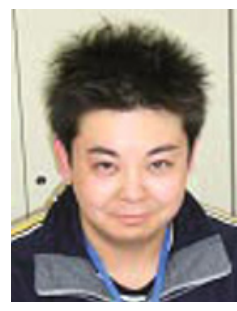

N Koite
PF Paradis (Senior Scientist) and T Ishikawa (Associate Professor) are within the staff of the Institute of Space and Astronautical Science of the Japan Aerospace Exploration Agency and $\mathrm{N}$ Koike is a student in instrumental science at Chiba Institute of Technology. Their investigations include the development of levitation furnaces and non-contact diagnostictechniques, and thermophysical and structural characterization of liquid metals. 


\section{References}

1 J.J. Cowa, C. Sneden, Nature, 2006, 440, 1151

2 V.E. McKelvey, Am. J. Sci., 1960, 258, 234

3 H. Schmidbaur, Ed., Gold, Progress in Chemistry, Biochemistry and Technology, Vol. XIV, Wiley, Chichester (1999)

4 T. lida, R.I.L. Guthrie, The Physical Properties of Liquid Metals, Clarendon Press, Oxford (1988)

5 P.-F. Paradis, T. Ishikawa, S. Yoda, ESA SP-454, Sorrento, Italy, Sept. 2000, 993 (2001)

6 T. Ishikawa, P.-F. Paradis, S. Yoda, Rev. Sci. Instrum., 2001, 72, 2490

7 W.-K. Rhim, S.-K. Chung, D. Barber, K.-F. Man, G. Gutt, A.A. Rulison, R.E. Spjut, Rev. Sci. Instrum., 1993, 64, 2961

8 A.T. Dinsdale, CALPHAD, 1991, 15, 317

9 E. Kaschnitz, G. Nussbaumer, G. Pottlacher, H. Jager, Intl J Thermophys., 1993, 14, 251

10 M. Gomez, L. Martin-Garin, P. Bedon, P. Desre, Bull. Soc. Chim. Fr., 1976 7-8, Pt 1, 1027
11 E. Gebhardt, J. Worwag, Z Metallkunde, 1951, 42, 358

12 B. Vinet, Magnusson, H. Fredriksson, P. Desre, J Colloid Interfac. Sci., 2002, 255, 363

13 L.-D. Lucas, Liquid Density Measurements “ from Techniques of Metals Research IV (2), R.A. Rapp, ed., p 219, Interscience Publishers, New-York, 1970

14 P.J. McGonigal, Phys. Chem., 1962, 66, 1686

15 G.P. Khilya, Yu.N. Ivachshenko, V.N. Eremenko, Izv. Akad. Nauk SSSR, Met., $1975,6,87$

16 K.C. Mills, Z. Li, Selected Values for Thermo-physical properties of Pure Metals, private communication, Oct. 2006

17 E. Gebhardt, S. Dorner, Z Metallkunde, 1951, 42, 353

18 J. Brillo, I. Egry, I. Ho, Intl. J Thermophys., 2006, 27 (2) 494

19 D.J. Steinberg, Metall. Trans., 1974, 5, 1341

20 C. Cagran, B. Wilthan, G. Pottlacher, Normal Spectal Emissivities (at $684.5 \mathrm{~nm}$ ) of liquid Gold, Rhenium, Titanium and Vanadium, Proceedings of Tempmeko 2004, Ed. Davor Zvizdic, Zagreb, Croatia, p. 1313,2005 